\title{
Review Article \\ A Social Constructivist Approach to Management of Primary Student Behavior
}

\author{
Ngo Vu Thu Hang* \\ Hanoi National University of Education, 136 Xuan Thuy, Cau Giay, Hanoi, Vietnam \\ Received 21 September 2020 \\ Revised 27 January 2021; Accepted 07 June 2021
}

\begin{abstract}
To teach lessons effectively, primary teachers need to effectively manage student behavior. Good student behavior management helps teachers receive a smooth coordination from students in classroom practices. This article provides knowledge base for primary teachers in managing student behavior and presents some possible measures to help primary teachers effectively manage student behavior. The article focuses on clarifying the issues of characteristic of primary students, principles of student behavior management, and measures of effective behavior management. The article applies a student-centered approach and social constructivism to provide measures to manage student behavior. The article not only works for primary teachers but also has many meanings for educational administrators and trainers in order to improving the implementation of General Education Program of 2018 in the current context of educational innovation.
\end{abstract}

Keywords: Behaviour management, primary education, social constructivism.

\footnotetext{
${ }^{*}$ Corresponding author.

E-mail address: hangnvt@hnue.edu.vn
}

https://doi.org/10.25073/2588-1159/vnuer.4473 


\title{
Quản lí hành vi học sinh tiểu học: Tiếp cận theo quan điểm kiến tạo xã hội
}

\author{
Ngô Vũ Thu Hằng* \\ Trường Đại học Su phạm Hà Nội, 136 Xuân Thủy, Cầu Giáy, Hà Nội, Việt Nam \\ Nhận ngày 21 tháng 9 năm 2020 \\ Chỉnh sửa ngày 27 tháng 01 năm 2021; Chấp nhận đăng ngày 07 tháng 6 năm 2021
}

\begin{abstract}
Tóm tắt: Để có được những giờ học hiệu quả, giáo viên tiểu học cần quản lí hiệu quả hành vi học sinh. Việc quản lí hành vi học sinh tốt sẽ giúp cho giáo viên nhận được sự phối hợp nhịp nhàng từ các em trong các hoạt động giáo dục, dạy học. Bài viết này cung cấp một số tri thức cần thiết cho giáo viên tiểu học trong việc quản lí hành vi học sinh, đồng thời trình bày một số biện pháp khả thi giúp giáo viên quản lí hiệu quả hành vi học sinh tiểu học. Bài viết tập trung vào làm rõ các vấn đề về đặc điểm, hành vi học sinh tiểu học, nguyên tắc quản lí hành vi học sinh, và một số biện pháp quản lí hành vi hiệu quả. Bài viết tiếp cận theo quan điểm kiến tạo xã hội và tư tưởng lấy học sinh làm trung tâm để đưa ra các biện pháp quản lí hành vi học sinh. Bài viết không chỉ có tác dụng với giáo viên tiểu học mà còn có nhiều ý nghĩa đối với các nhà quản lí giáo dục, các nhà đào tạo sinh viên sư phạm tiểu học nhằm góp phần nâng cao chất lượng giáo dục phổ thông trong bối cảnh đổi mới giáo dục hiện nay.
\end{abstract}

Từ khóa: Quản lí hành vi, giáo dục tiểu học, kiến tạo xã hội.

\section{1. Đặt vấn đề}

Để có được những giờ học hay, để hoạt động giáo dục học sinh được hiệu quả, giáo viên tiểu học không chỉ cần đến kiến thức môn học, năng lực dạy học mà còn cần cả kĩ năng quản lí hành vi học sinh. Việc quản lí hành vi học sinh hiệu quả là nền tảng, điều kiện tiên quyết cho sự thành công của các hoạt động giáo dục, dạy học ở nhà trường tiểu học. Thực tế hiện nay cho thấy, kĩ năng này vẫn chưa được giáo viên tiểu học thực hiện tốt trong nhiều tiết lên lớp. Để chuẩn bị cho giờ học, rất nhiều giáo viên khi soạn giáo án đều tập trung vào quy trình và nội dung kiến thức bài học. Chính vì sự quan tâm chưa đúng mức nên nhiều giáo viên, đặc biệt là các giáo viên trẻ mới ra trường, đã có những tiết học chưa thành công. Nhiều giáo viên tiểu học đã trở nên tự ti, hoài nghi năng lực dạy học của bản thân, thậm chí thấy hoang

\footnotetext{
* Tác giả liên hệ.

Địa chỉemail: hangnvt@hnue.edu.vn

https://doi.org/10.25073/2588-1159/vnuer.4473
}

mang và dao động trước sự lựa chọn nghề nghiệp của mình. Họ không nhận thấy rằng nút thắt của vấn đề nằm ở chính kĩ năng quản lí hành vi học sinh của họ. Chỉ cần họ tập trung vào xử lí nút thắt này, trang bị tốt hơn các kiến thức và kĩ năng về quản lí hành vi học sinh, nhiều vấn đề của giờ học có thể được giải quyết dễ dàng và giúp họ có những bài dạy hiệu quả hơn.

Thực tiễn lớp học và học sinh tiểu học bao giờ cũng sống động hơn tất cả những trang sách giáo khoa hay kế hoạch bài dạy. Các lớp học không giống nhau và các học sinh trong một lớp học cũng không hề giống nhau. Giáo viên tiểu học cần hiểu rõ đặc điểm lớp học của mình, đặc điểm học sinh của mình để có những biện pháp quản lí hành vi học sinh hiệu quả, từ đó có thể thực hiện tốt các hoạt động dạy học trên lớp. Bài viết này là một nghiên cứu cụ thể nằm trong một dự án nghiên cứu lớn về việc xây dựng và đánh giá các biện pháp quản lí lớp ở tiểu học theo tiếp cận kiến tạo xã hội, ở đó việc quản lí hành vi học sinh là một nội dung cốt lõi. Các nhà nghiên cứu tin rằng nếu giáo viên tiểu học được trang bị tốt hơn về kiến thức và kĩ năng 
quản lí hành vi học sinh, họ có thể thực hiện thành công những bài dạy đổi mới theo định hướng phát triển năng lực, đáp ứng mục tiêu giáo dục được đề ra trong Chương trình Giáo dục Phổ thông 2018 [1]. Việc tìm hiểu của nhóm nghiên cứu cho thấy sự ra đời của Chương trình Giáo dục Phổ thông 2018 đã thúc đẩy rất nhiều nghiên cứu về thiết kế bài học nhằm phát triển năng lực học sinh, về phương pháp, kĩ thuật dạy học tích cực, về đổi mới trong đánh giá việc học tập của học sinh. Mặc dù vậy, vẫn có khoảng trống đáng kể các nghiên cứu về xây dựng và đánh giá các biện pháp quản lí hành vi học sinh tiểu học. Sự thiếu vắng những tri thức này có thể là nguyên nhân của một số khó khăn trong tổ chức dạy học, trong việc tạo lập môi trường lớp học kiến tạo, tích cực. Do vậy, nghiên cứu này được thực hiện nhằm hệ thống hóa và cung cấp những tri thức ban đầu cần thiết giúp giáo viên tiểu học có thể quản lí hiệu quả hành vi học sinh tiểu học. Nghiên cứu tập trung vào làm rõ các vấn đề: i) Đặc điểm và hành vi của học sinh tiểu học; ii) Nguyên tắc quản lí hành vi học sinh tiểu học; và iii) Các chiến thuật, biện pháp quản lí hành vi học sinh tiểu học. Tác giả của bài viết tiếp cận theo quan điểm kiến tạo xã hội [2-4] với tư tưởng lấy học sinh làm trung tâm, nhằm trả lời cho câu hỏi nghiên cứu chính: Để quản lí hiệu quả hành vi học sinh tiểu học, giáo viên cần làm gì và làm nhu thế nào? Để trả lời câu hỏi này, tác giả sử dụng phương pháp nghiên cứu lí thuyết với việc tổng hợp, phân tích các tài liệu liên quan đến vấn đề nghiên cứu. Bài viết giúp cung cấp những tri thức có thể sử dụng làm cơ sở cho việc nghiên cứu, đánh giá thực trạng năng lực quản lí hành vi học sinh tiểu học của giáo viên theo quan điểm kiến tạo xã hội, từ đó, giúp đẩy mạnh chất lượng và hiệu quả của hoạt động này tại các nhà trường phổ thông.

\section{Nội dung}

\subsection{Thế nào là quản lí hành vi học sinh?}

Quản lí hành vi học sinh được cho là một phần của hoạt động của quản lí lớp học $[4,5]$, được thực hiện bởi giáo viên (là chủ yếu) và học sinh nhằm giúp cho hoạt động giáo dục, dạy học ở trên lớp đạt được mục tiêu đề ra. Đó là những nỗ lực, cố gắng của giáo viên nhằm giám sát, kiểm soát được các hành vi của học sinh ở trên lớp để phòng tránh hoặc ứng phó với những hành động không mong muốn của học sinh, từ đó có được phối hợp nhịp nhàng của học sinh trong quá trình giáo dục, dạy học.

Nhiều nhà nghiên cứu đều cho rằng kĩ năng quản lí hành vi học sinh là quan trọng nhất để quyết định sự thành công của việc giáo dục [6]. Họ đã chỉ ra trong số các yếu tố có ảnh hưởng đến kết quả học tập của học sinh thì các yếu tố liên quan đến quản lí hành vi ở tốp đầu trong danh sách [4, 7]. Nhiều nghiên cứu về kĩ năng dạy học hiệu quả và phân tích kế hoạch dạy học của giáo viên cho thấy những giáo viên giỏi đều thể hiện sự nổi trội hơn về kĩ năng quản lí hành vi học sinh từ trong kế hoạch bài học đến giảng dạy trên lớp $[8,9]$. Nhiều nhà giáo dục cho rằng nếu giáo viên không có được sự hợp tác của học sinh thì việc dạy học hiệu quả không thể diễn ra. Hơn nữa, việc quản lí tồi còn làm lãng phí thời gian trên lớp, làm giảm thời gian làm bài của học sinh và làm sa sút chất lượng của môi trường học tập.

\subsection{Quan điểm kiến tạo xã hội}

Quan điểm kiến tạo xã hội $[10,11]$ nhấn mạnh tính tích cực, chủ động, riêng biệt của học sinh như một con người chứ không phải như một robot. Theo đó, giáo dục, dạy học là hoạt động đào tạo, phát triển con người, chứ không phải là hoạt động "đúc người" theo khuôn mẫu cứng nhắc nào đó để tạo ra những sản phẩm "học sinh công nghiệp". Giáo dục và dạy học là một quá trình, phải gần gũi và gắn liền với cuộc sống thực của học sinh, cần được xuất phát từ học sinh, tập trung vào học sinh, và để phục vụ cho lợi ích của chính học sinh [10]. Học sinh cần được tham gia vào các hoạt động giáo dục, học tập với toàn bộ con người của mình như một chỉnh thể toàn diện (cả về mặt thể chất vật lí lẫn tinh thần, cảm xúc), và các yếu tố được coi trọng bởi giáo viên, để đạt được không chỉ kiến thức mà quan trọng hơn, còn là những kĩ 
năng thiết yếu và thái độ tích cực, qua đó hình thành nên những năng lực, phẩm chất cần thiết giúp các em sau này làm chủ cuộc sống của mình và xây dựng cuộc sống chung trong tương lai [1]. Một số nguyên lí của quan điểm kiến tạo xã hội $[2,10]$ có ý nghĩa làm nền tảng cho việc thực hiện các hoạt động quản lí lớp của giáo viên tiểu học bao gồm:

i) Giáo dục là hoạt động mang tính xã hội;

ii) Môi trường giáo dục và văn hóa lớp học có ý nghĩa quan trọng đối với việc học của học sinh;

iii) Học sinh là trung tâm và là chủ thể tích cực của hoạt động học tập;

iv) Giáo viên đóng vai trò là người trợ giúp, tổ chức, quản lí học sinh hơn là người truyền thụ kiến thức và phán xét tối cao;

v) Trải nghiệm và hợp tác là cách tiếp cận giáo dục có ý nghĩa và hữu hiệu đối với học sinh;

vi) Tất cả các thuộc tính cá nhân con người như thể chất, thái độ, cảm xúc, hành vi, giá trị, ... của học sinh cần được quan tâm và kết nối với nhau trong quá trình học sinh tham gia vào hoạt động giáo dục;

vii) Giáo dục là một quá trình giúp học sinh phát triển năng lực và phẩm chất chứ không phải là giúp học sinh đạt được kết quả cuối cùng về kiến thức.

Giáo dục theo quan điểm kiến tạo xã hội không phải là để học sinh thích học gì thì học, thích làm gì thì làm, hoàn toàn tự do trong lớp học. Ý nghĩa sâu xa của giáo dục theo quan điểm kiến tạo xã hội là nhằm giúp cho học sinh không chỉ biết học cái gì, làm cái gì mà quan trọng hơn còn là biết học như thế nào, làm như thế nào và tại sao cần làm như vậy. Nói cách khác, nó giúp cho học sinh tham gia vào các hoạt động học tập một cách có ý thức và làm chủ được các hành vi học tập của mình. Giáo dục theo quan điểm kiến tạo xã hội khác lối giáo dục truyền thống ở chổ nó có sự cởi trói, khai phóng người học với sự thúc đẩy tính chủ động, tích cực, tư duy độc lập của người học nhưng vẫn bám theo nguyên tắc nhất định. Do đó, sự cởi mở, tự do của học sinh trong lớp học kiến tạo xã hội là sự cởi mở, tự do trong khuôn khổ, có định hướng, có mục đích.
Quản lí hành vi học sinh tiếp cận theo quan điểm kiến tạo xã hội sẽ giúp cho học sinh hiểu có ý thức rằng được cái gì mình nên làm và cái gì thì không nên. Một người giáo viên kiến tạo xã hội không quản lí hành vi học sinh bằng sự áp đặt, độc đoán, duy trì mối quan hệ bất bình đẳng người trên (giáo viên) - quyền uy, người dưới (học sinh) - phục tùng. Trái lại, cô khuyến khích và tạo ra một môi trường học tập cởi mở, dân chủ với quy định được thống nhất rõ ràng, học sinh được phép nói lên ý kiến riêng, giải thích cho các hành động của mình. Người giáo viên kiến tạo xã hội cũng quản lí hành vi học sinh bằng cách duy trì mối quan hệ thân thiện, bình đẳng giữa giáo viên với học sinh, lấy lợi ích của học sinh làm trọng tâm cho các quyết định, hoạt động thực hiện ở lớp học.

\subsection{Một số đặc điểm của học sinh tiểu học}

Học sinh tiểu học có những đặc điểm riêng về thể chất, nhận thức, cảm xúc và có những nhu cầu khác với người lớn [10]. Cụ thể, học sinh tiểu học có những đặc điểm sau:

i) Đặc điểm thể chất. Cơ thể trẻ em là nền tảng vật chất của trí tuệ và tâm hồn. Nền tảng phải vững thì trí tuệ và tình cảm mới có khả năng phát triển tốt. Sự phát triển thể chất của học sinh tiểu học có những đặc điểm sau:

Thể lực phát triển tương đối đồng đều. Mỗi năm, chiều cao chỉ tăng thêm khoảng $4 \mathrm{~cm}$, trọng lượng cơ thể thì có thể tăng $2 \mathrm{~kg}$.

Có thể tiến hành những vận động cơ bản (đi, đứng, chạy, nhảy, bò, giữ thăng bằng,...) một các mềm mại, nhanh và chính xác. Bộ xương lúc này đang bắt đầu vào giai đoạn cứng đần nên còn nhiều mô sụn và phát triển chưa hoàn thiện, cân đối, đặc biệt là xương tay, ngón tay còn yếu.

Hệ thần kinh đang thời kì phát triển mạnh. Đây là thời kì não bộ phát triển cả về khối lượng, trọng lượng lẫn cấu tạo, đến khoảng 9 - 10 tuổi, não của các em căn bản được hoàn thiện và chất lượng của nó sẽ được giữ lại trong suốt cuộc đời. Đây cũng là giai đoạn mà sự hình thành các phản xạ có điều kiện diễn ra nhanh và nhiều.

Hệ tuần hoàn chưa hoàn chỉnh. Cơ tim phát triển mạnh, nhưng nhịp tim vẫn còn nhanh, 
huyết áp động mạnh thấp làm cho các em chóng mệt và dễ xúc động;

ii) Đặc điểm tâm lí, nhận thức. Từ khi ra đời đến khi bắt đầu đi học tiểu học, môi trường sống xung quanh góp phần tạo nên những thành tựu phát triển tâm lý, nhận thức nhất định ở trẻ. Sự kết hợp của những thành tựu đó đã làm nên những đặc điểm tâm lí của học sinh tiểu học, bao gồm:

Dễ thích nghi và tiếp nhận cái mới, nhưng thiếu sự tập trung cao độ, khả năng ghi nhớ và chú ý có chủ định chưa được phát triển mạnh, tính hiếu động, dễ xúc động còn bộc lộ rõ nét. Các em nhớ rất nhanh và quên cũng nhanh.

Tri giác của học sinh tiểu học phản ánh những thuộc tính trực quan, cụ thể của sự vật, hiện tượng và xảy ra khi chúng trực tiếp tác động lên giác quan. Tri giác giúp cho các em định hướng nhanh chóng và chính xác hơn trong thế giới. Tri giác còn giúp cho các em điều chỉnh hoạt động một cách hợp lý.

Tư duy của học sinh tiểu học nhìn chung vẫn là tư duy cụ thể, dựa vào những đặc điểm trực quan của đối tượng và hiện tượng cụ thể. Trong sự phát triển tư duy ở học sinh tiểu học, tính trực quan cụ thể thể hiện rõ ở các lớp đầu cấp và sau đó chuyển dần sang tính khái quát ở các lớp cuối cấp.

Học sinh tiểu học thường có nhiều nét tính cách tốt như hồn nhiên, ham hiểu biết, lòng thương người, lòng vị tha.

Đối với học sinh tiểu học, tình cảm có vị trí đặc biệt vì nó là khâu trọng yếu gắn nhận thức với hoạt động của trẻ em. Tình cảm tích cực sẽ kích thích trẻ em nhận thức và thúc đẩy trẻ em hoạt động. Tình cảm học sinh tiểu học được hình thành trong đời sống và trong quá trình học tập của các em.

Việc hiểu được đặc điểm thể chất, nhận thức, cảm xúc của học sinh tiểu học sẽ giúp giáo viên có những cách quản lí hành vi phù hợp, nhờ đó, hoạt động giáo dục, dạy học sẽ hiệu quả hơn.

\subsection{Hành vi hoc sinh tiểu học}

Không phải lúc nào học sinh tiểu học cũng có những hành vi phù hợp và không phải học sinh nào cũng luôn có những hành vi không phù hợp trong quá trình học tâp ở trường. Hành vi của các em bị chi phối bởi nhận thức và cảm xúc của các em và cả hai yếu tố này đều ảnh hưởng bởi cách giáo dục của nhà trường và giáo viên thực hiện đối với các em. Động lực chính thúc đẩy hành vi của các em chính là cảm xúc. Trong thực tế, cảm xúc tức thời của các em thường lấn át, che mờ hoặc thậm chí khống chế lý trí của các em. Điều đó có nghĩa là học sinh tiểu học thường hành động xuôi theo những cảm xúc của mình nhiều hơn là lý lẽ về những điều tốt - xấu. Các em chế ngự cảm xúc kém hơn người lớn và thường để cảm xúc dẫn dắt hành vi. Do đó, hành vi của các em sẽ thiên về bản năng hơn so với người trưởng thành, có tính bốc đồng, bột phát và chịu sự ảnh hưởng của cảm xúc lâm thời. Trong khi đó, cảm xúc lâm thời lại là thứ dễ thay đổi. Chính vì thế, hành vi của các em cũng có thể dễ dàng thay đổi và điều chỉnh để trở nên phù hợp hơn. Sự tác động này được thực hiện càng sớm càng tốt, tránh để trở thành thói quen trong hành vi vì khi ấy sự thay đổi sẽ trở nên khó khăn hơn.

Học sinh tiểu học cần được giáo dục để có thể làm chủ cảm xúc của mình, lí tính hơn, thay vì chỉ cảm tính, từ đó có những hành vi phù hợp. Một giáo viên quản lí tốt hành vi học sinh là người có khả năng giúp học sinh tự quản lí hành vi của mình tốt. Để làm được điều đó, người giáo viên cần quan sát và điều chỉnh hành vi chưa phù hợp của học sinh sao cho phù hợp với chuẩn quy định đề ra. Hoạt động quan sát cần được giáo viên thực hiện xuyên suốt các hoạt động của học sinh diễn ra ở trường học, trong lớp học, gắn liền với hoạt động bao quát lớp và tập trung vào những vấn đề liên quan đến ý thức, kỉ luật ở học sinh.

\subsection{Nguyên tắc quản lí hành vi hiệu quả}

Quản lí hành vi hiệu quả là việc thực hiện hợp lí các biện pháp quản lí hành vi, làm giảm những hành động, việc làm không mong muốn của học sinh đến mức tối thiểu, giúp cho các hoạt động giáo dục được thực hiện ổn định và hiệu quả $[3,4]$. Những nguyên tắc giáo viên tiểu học cần tuân thủ để quản lí hành vi hiệu quả được thể hiện trong Hình 1 dưới đây: 


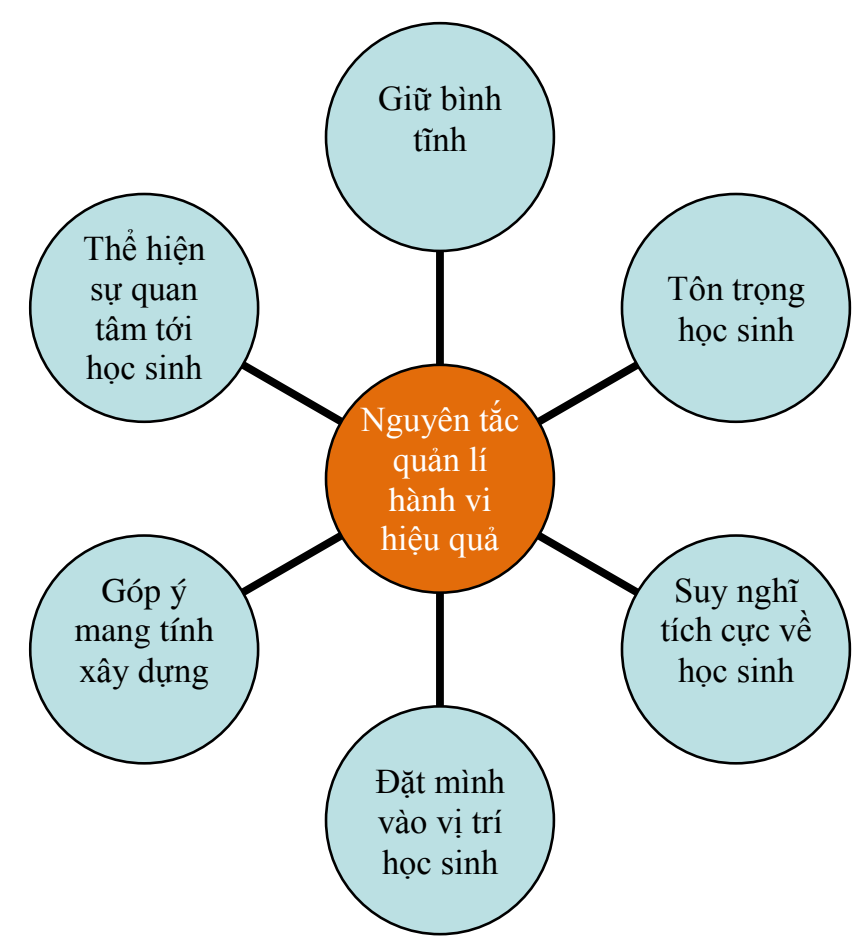

Hình 1. Nguyên tắc quản lí hành vi hiệu quả.

\subsubsection{Giữ bình tĩnh}

Giáo viên cần cố gắng hiểu học sinh về ba mặt - sinh học, xã hội và tâm lí - trước khi đưa ra quyết định xử lí tình huống. Ở tuổi học sinh tiểu học, các em vẫn còn đang phát triển về mặt tâm lí và thể chất, vậy nên khả năng điều khiển hành vi của các em còn hạn chế. Giáo viên vì thế phải luôn giữ tâm thế bình tĩnh trước khi đứng trước một tình huống liên quan đến hành vi không mong muốn của học sinh để tránh gây ra những hệ quả không đáng có (ví dụ: khiến học sinh bị tổn thương bằng lời nói của mình, khiến học sinh mất trước mặt các bạn trong lớp,...).

Một số cách để giáo viên giữ bình tĩnh:

i) Hít thở sâu 3 lần;

ii) Đếm từ 1 đến 10 trong đầu;

iii) Tưởng tượng trong đầu một viễn cảnh yên bình;

iv) Chuyển hướng suy nghĩ về những điều tích cực.

Để giữ được sự bình tĩnh khi giao tiếp với học sinh, giáo viên cần: i) Xây dựng mối quan hệ tình cảm, thân thiện với học sinh: Khi giáo viên có một mối liên kết với học sinh về mặt tình cảm, khả năng cao học sinh sẽ thường xuyên tâm sự với giáo viên hơn. Từ đó, giáo viên có thể hiểu học sinh hơn và sẽ thông cảm với các em hơn khi các em có những hành vi không tốt, thay vì vội vàng đưa ra những nhận xét không hay về học sinh;

ii) Nói chuyện với học sinh bằng giọng nói ấm áp, thân thiện: Sau khi học sinh có hành vi không mong muốn, giáo viên thay vì lên giọng với các em, cô có thể bình tĩnh, dừng lại trong giây lát và lên tiếng khi sẵn sàng. Khi lên tiếng, giáo viên nên dùng tông trầm để nói. Áp dụng cách này không chỉ giúp giáo viên bình tĩnh hơn khi giải quyết tình huống mà cũng tránh được việc làm học sinh bị mất mặt với bạn bè;

iii) Nói chậm, từ tốn: Bên cạnh việc dùng tông trầm để nói, giáo viên cũng nên điều chỉnh tốc độ nói của mình thật chậm rãi. Nói chậm thể hiện sự bình tĩnh và nó có thể khiến người nói bình tĩnh hơn một cách vô thức; 
iv) Tránh đưa ra những nhận xét vội vàng về học sinh. Học sinh luôn có những lý do nhất định nào khi các em cư xử không đúng chuẩn mực. Giáo viên không nên bỏ qua việc xem xét những khía cạnh liên quan trước khi quyết định lời nói, cách thức kỉ luật các em vì điều đó có thể khiến học sinh bị tổn thương.

\subsubsection{Tôn trọng học sinh}

Giáo viên cần tôn trọng học sinh, kể cả những học sinh mắc lỗi. Điều này là cần thiết vì chỉ bằng cách đó giáo viên mới có thể duy trì được sự tôn trọng của học sinh đối với mình. Khi giáo viên và học sinh có sự tôn trọng dành cho nhau thì đôi bên còn có thể ngồi lại, nói chuyện, góp ý và nhắc nhở cho nhau và có sự tiếp thu ở phía đôi bên. Để thể hiện sự tôn trọng học sinh, giáo viên cần:

i) Lắng nghe ý kiến của học sinh: Lắng nghe là biểu hiện của sự tôn trọng vì nó thể hiện rằng người nghe trân trọng ý kiến mà người nói đưa ra. Một khi đã lắng nghe thì nên thực sự tập trung nghe, công thêm sự quan sát cả ngôn ngữ cơ thể của người nói, để thể hiện rằng mình coi trọng người nói cũng như những gì họ nói, chứ không phải giả vờ nghe cho có. Điều này sẽ khuyến khích người nói hơn trong việc đưa ra một hệ thống thông tin đầy đủ và rõ ràng thay vì cho bạn một phiên bản lan man và mơ hồ;

ii) Không ngắt lời học sinh: Ngắt lời người khác thường được coi là một hành động khiếm nhã và nó thường được xem là bạn không coi trọng ý kiến của người nói và không muốn nghe những điều họ muốn nói. Vậy nên, việc không ngắt lời học sinh là một biểu hiện tích cực cho sự tôn trọng, kể cả khi những ý kiến học sinh đưa ra còn chưa chính xác;

iii) Không phân biệt đối xử giữa các học sinh với nhau: Trong một lớp học, học sinh rất đa dạng về thành phần, học lực, tính cách, khả năng,... Giáo viên cần đảm bảo mình có sự khách quan trong đối xử với học sinh, không thiên vị hay định kiến với học sinh nào;

iv) Sã̃n sàng nhận sai: Nếu có điểm nào sai sót về phía bản thân mình mà góp phần gây nên tình huống không mong muốn thì cần phải bình tĩnh nhận định, tự nhận thiếu sót và sửa sai. Bằng cách đó, giáo viên đang khuyến khích học sinh của mình làm điều tương tự.
2.5.3. Thể hiện sự quan tâm tới học sinh

Việc thể hiện sự quan tâm tới học sinh của giáo viên liên quan đến mối quan hệ cho và nhận. Khi giáo viên thể hiện sự quan tâm, học sinh sẽ đáp lại bằng sự chia sẻ và quan tâm tương ứng. Từ đó, thầy và trò sẽ có một mối quan hệ tình cảm gắn kết với nhau. Trên nền tảng đó, hai bên có thể thông cảm cho nhau hơn và hợp tác với nhau tốt hơn trong việc dạy và học. Để thể hiện sự quan tâm tới học sinh, giáo viên nên:

i) Nhớ tên học sinh. Đây là yếu tố cơ bản để tạo lập một mối quan hệ. Chỉ việc nhớ một chi tiết nhỏ này thôi cũng là một cách một người thể hiện sự quan tâm tới học sinh, nhất là khi lớp học thường có rất nhiều học sinh. Giáo viên nhớ tên học sinh thể hiện rằng cô quan tâm và cô muốn gắn bó với các em;

ii) Nhớ sinh nhật học sinh. Chỉ việc nhớ một chi tiết nhỏ này thôi cũng là một cách một người thể hiện sự quan tâm tới người khác. Với quan hệ thầy - trò cũng vậy. Nhất là với một đứa trẻ, bé sẽ rất cảm kích và yêu mến người có thể chủ động nhớ sinh nhật của bé. Giáo viên không nhất thiết phải "lưu" những thứ ngày tháng sinh nhật học sinh vào trí nhớ mà có thể làm một cái bảng thông tin trong đó có sinh nhật các em, hay cho học sinh điền sinh nhật vào lịch chung của lớp;

iii) Hỏi thăm học sinh thường xuyên. Chỉ bằng những câu hỏi đơn giản như "Sáng nay con ăn gì?" "Hôm nay ai buộc tóc cho con?" hay "Hôm nay tết bím của con xinh quá!", giáo viên đã có thể thể hiện tình cảm quan tâm tới học sinh và các em sẽ nhận những lời đó với niềm vui thích vô cùng;

iv) Hỏi thăm và tâm sự với học sinh khi các em buồn. Ai cũng quý trọng người ở bên ta khi ta buồn, trẻ em cũng vậy. Thế nên, giáo viên nên tỏ thiện ý muốn hỏi thăm học sinh để em có thể mở lòng tâm sự với mình.

2.5.4. Suy nghĩ tích cực về học sinh

Những biểu hiện cho thấy giáo viên là người có khuynh hướng suy nghĩ tích cực về học sinh:

i) Luôn khẳng định, đề cao những ưu điểm, những nét tích cực ở học sinh;

ii) Để học sinh nói ra ý kiến của mình; 
iii) Khi học sinh đưa ra những ý kiến chưa đúng, giáo viên động viên và khen những ý đúng của học sinh;

iv) Khi học sinh có hành vi không mong đợi, giáo viên cho học sinh cơ hội để giải thích lí do cho hành động của mình;

Động viên học sinh bày tỏ ý kiến trong giờ học dù là học sinh đó thường xuyên đưa ra những ý kiển phát biểu chưa chính xác

Tạo cơ hội và động viên học sinh thể hiện bản thân nếu các em thích trong những hoạt động văn - thể - mĩ dù học sinh đó không nổi trội trong lĩnh vực đó.

2.5.5. Đặt mình vào vị trí của học sinh

Đặt mình vào vị trí của học sinh hay còn được biết đến là nguyên tắc định vị. Khi có một tình huống cần phải xử lí, giáo viên cần nhớ lại cảm giác khi mình còn ở tuổi các con, cố gắng nhìn và hiểu thế giới theo các của các con để có thể hiểu và thấu cảm hơn đối với học sinh. Những biểu hiện cho thấy giáo viên biết đặt mình vào vị trí của học sinh:

i) Bình tĩnh trước những tình huống học sinh có những hành vi không mong đợi: Sự bình tĩnh thể hiện sự thấu hiếu và cho thấy rằng giáo viên đang bỏ chút thời gian suy nghĩ, đánh giá vấn đề để hiểu tại sao học sinh lại hành xử như vậy;

ii) Suy nghĩ trước khi đưa ra quyết định: Khi đã bình tĩnh bỏ thời gian ra đánh giá tình huống, giáo viên cần xem xét để đưa ra cách giải quyết phù hợp với những đánh giá đã thực hiện;

iii) Lắng nghe lý do của học sinh: Trên cơ sở của những đánh giá đã thực hiện, giáo viên nên lắng nghe ý kiến của học sinh để tránh trường hợp đưa ra quyết định sai. Bằng cách này, giáo viên có thể mở rộng vốn hiểu biết của mình về hành động, hành vi của học sinh, góp phần đưa ra những cách giải quyết hợp lí hơn cho những lần sau;

iv) Tôn trọng lý do của học sinh đưa ra: Không chụp mũ hay phủ nhận lý do của học sinh thể hiện sự thấu hiểu của giáo viên. Ngoài ra, bằng cách này, giáo viên sẽ nhận về không chỉ sự tôn trọng của học sinh mà còn những hiểu biết về hành vi học sinh.

Đặt mình vào vị trí của học sinh, giáo viên nên:

i) Cho học sinh cơ hội để giải thích lý do cho hành động của mình; ii) Cố gắng dùng suy nghĩ của một đứa trẻ để đánh giá chứ không phải của người lớn;

iii) Tránh đưa ra quyết định vội vàng hay gạt lý do của học sinh và coi đó là vô lý hay suy nghĩ trẻ con.

2.5.6. Đưa ra góp ý mang tính xây dựng đối với học sinh

Để có thể đưa ra góp ý mang tính xây dựng đối với học sinh, giáo viên nên:

i) Góp ý rõ ràng với học sinh về thiếu sót cụ thể, việc làm cụ thể. Những góp ý chung chung thay vì chỉ rõ ra hành động chưa phù hợp sẽ khiến học sinh bối rối. Có thể ngay lúc đó học sinh sẽ ngưng hành vi không đúng của mình lại nhưng khả năng em đó tái phạm là rất cao;

ii) Phân tích tình hình trước khi đưa ra nhận xét góp ý vì một tình huống như học sinh mất trật tự trong lớp sẽ có tính chất khác nhau tuỳ thuộc vào tính cách và môi trường xung quan lúc đó;

iii) Giữ thái độ thân thiện với học sinh khi bày tỏ ý kiến góp ý. Thái độ khi truyền đạt một thông điệp có ảnh hưởng rất lớn đế sự tiếp nhận nơi người nghe. Nếu thấy thái độ giáo viên quá gay gắt (như nặng lời, quát mắng,...), học sinh sẽ miễn cưỡng nghe theo tại thời điểm đó, nhưng em đó sẽ không ấn tượng bằng khi giáo viên lựa chọn cách truyền đạt thân thiện hơn (như kể một câu chuyện có tính giáo dục nào đó).

iv) Lựa chọn ngôn từ đơn giản, phù hợp với học sinh nhỏ sao cho khi giải thích, góp ý học sinh có thể tiếp thu một cách dễ dàng nhất;

v) Tránh thể hiện thái độ tức giận khi nói chuyện hay sử dụng ngôn từ mang tính xúc phạm với học sinh.

\section{Các chiến thuật, biện pháp quản lí hành vi học sinh tiểu học}

\subsection{Xây dựng nội quy và quy tắc}

3.1.2. Xác định các nội quy và quy tắc ứng xử cụ thể cho lớp học

Đặt ra chuẩn mưc ứng xủ chung. Quy tắc ứng xử chung trong lớp học thể hiện những kì vọng chung về các ứng xử của học sinh. Bên cạnh đó, nó giúp luyện cho học sinh thói quen ứng xử tốt. Ở cấp tiểu học, những quy tắc và 
nội quy dành cho cách ứng xử của học sinh thường có những nội dung như sau:

i) Lễ phép và tôn trọng thầy cô;

ii) Thân thiện và luôn sẵn sàng giúp đỡ bạn bè;

iii) Giữ gìn đồ dùng của lớp, của bạn và của bản thân;

iv) Giữ gìn vệ sinh lớp học

Đặt ra nếp bắt đầu, kết thúc. Việc thực hiện những hoạt động bắt đầu và kết thúc giờ học, ngày học một cách liên tục và lặp lại giúp tạo cho học sinh có một sự định hình về khoảng thời gian học tập trên lớp. Ở cấp tiểu học, những quy tắc và nội quy dành cho cách ứng xử của học sinh thường có những nội dung như sau:

i) Trước khi vào bài học, học sinh cần phải làm một hoạt động cụ thể (Ví dụ: để sã̃n sách vở, đồ dùng trên bàn; học sinh vỗ tay chào đón giáo viên,...);

ii) Tiến hành các hoạt động mang tính bắt buộc (ví dụ: điểm danh,...);

iii) Sau khi tiết học, buổi học kết thúc, học sinh cần thực hiện một hoạt động cụ thể (ví dụ: chào giáo viên; thu dọn bàn ghế; cất dọn tài liệu và đồ dùng học tập,...);

Yêu cầu khi sủ dụng tài liệu và thiết bị. Ở cấp tiểu học, những quy tắc và nội quy dành cho cách ứng xử của học sinh thường có những nội dung như sau:

i) Cách thức thu, phát tài liệu, đồ dùng;

ii) Cách cất giữ tài liệu, đồ dùng;

iii) Cách thức sử dụng tài liệu, đồ dùng;

Hoạt động nhóm. Những quy tắc và nội quy dành cho cách ứng xử của học sinh thường có những nội dung như sau:

i) Tinh thần tham gia hoạt độn;

ii) Những yêu cầu mà thành viên trong nhóm cần thực hiện hoặc đạt được;

iii) Cách giao tiếp giữa các thành viên với nhau.

Làm việc cá nhân, độc lập. Ở cấp tiểu học, những quy tắc và nội quy dành cho cách ứng xử của học sinh thường có những nội dung như sau:

i) Học sinh chú ý nghe giáo viên phổ biến, hướng dẫn;

ii) Thái độ khi tham gia thực hiện hoạt động; iii) Giao tiếp với các học sinh khác;

iv) Yêu cầu về vấn đề di chuyển trong khi thực hiện hoạt động;

v) Yêu cầu về hành vi sau khi hoàn thành xong nhiệm vụ.

3.1.2. Thu hút học sinh tham gia thiết kế nội quy và quy tắc

Mỗi lớp học cần một bộ nội quy nhất định, nhưng trước khi đưa vào áp dụng một bộ nội quy lớp học, giáo viên cần tổ chức một buổi thảo luận, trao đổi với học sinh về những nội dung của những nguyên tắc. Trong quá trình xây dựng nội quy học sinh có thể sử dụng những kiến thức các em đã có về thực tế cuộc sống để đóng góp những ý kiến cho từng phần của nội quy lớp. Công việc của giáo viên khi đó là tổng hợp lại những ý kiến của học sinh và chọn lọc những nội dung phù hợp với lớp học đó.

Sau đó, giáo viên có thể trình bày cho học sinh những quy tắc mình đã đưa ra, giải thích và nêu ví dụ cho từng nội quy và quy tắc. Khi giáo viên trình bày bản nội quy đã qua chọn lọc, học sinh có thể thảo luận thêm về các ý tường mà giáo viên đưa ra và để xuất các quy tắc thay thế khác, hay nêu ý kiến bổ sung hoặc bỏ bớt các quy tắc nào. Một cuộc thảo luận như vậy sẽ khiến học sinh cảm thấy giáo viên quan tâm đến ý kiến và sự đóng góp của mình. Qua đó học sinh sẽ cảm thấy bị thuyết phục và sẵn sàng tuân thủ theo các quy tắc và nội quy được thông qua. Trong trường hợp đa phần những ý kiến học sinh đưa ra là không phù hợp với lớp học đó, giáo viên với tư cách người hướng dẫn lớp học sẽ đưa ra quyết định sau khi cân nhắc kĩ.

\subsection{Xây dựng nền nếp, kỉ luật}

Có rất nhiều cách giáo viên có thể áp dụng để kỉ luật học sinh mỗi khi các em mắc lỗi, nhưng thực tế chỉ có một vài nhóm biện pháp lớn mà trong đó bao gồm các biện pháp có tính chất tương tự nhau. Một trong những cách phân chia được biết đến nhiều nhất là nhóm 5 biện pháp của R. J. Marzano [4]. Năm nhóm biện pháp đó là:

Phản ứng của giáo viên. Phản ứng bằng hành động và lời nói của là cách đơn giản nhất và dễ thực hiện nhất để công nhận, khen thưởng những hành vi phù hợp cũng như nhận biết 
những hành vi không phù hợp của học sinh. Những phản ứng thường được giáo viên lựa chọn áp dụng trong lớp học của mình bao gồm:

i) Ra hiệu bằng ánh mắt với học sinh mắc lỗi bằng cách đến gần học sinh đó. Đây là cách tinh tế nhưng hiệu quả để cảnh báo cho học sinh rằng em đang cư xử không đúng. Biện pháp này phù hợp nhất trong những tình huống giáo viên muốn "cảnh cáo" học sinh hay đưa ra thông điệp để học sinh biết rằng người thầy ý thức được việc học sinh chuẩn bị hoặc đang làm;

ii) Dùng những tính hiệu hình thể như đưa ngón tay lên môi hoặc lắc đầu để biểu thị sự không tán thành hành động của học sinh. Cách thức tương đương với việc ra hiệu lệnh bằng ngôn từ nhưng nó không đi kèm với sự răn đe như khi giáo viên sử dụng ngôn từ. Vậy nên, khi sử dụng biện pháp này, học sinh sẽ không bị cảm thấy áp lực nặng nề về mặt tinh thần như khi bị giáo viên nhắc nhở bằng lời nói;

iii) Nhắc nhở học sinh đó một cách đơn giản - nhắc nhở riêng và càng tinh tế càng tốt - hoặc cũng có thể chỉ ra hành vi phù hợp mà bạn muốn học sinh thực hiện;

iv) Trong trường hợp học sinh không có phản ứng với những can thiệp tinh tế, các đơn giản nhất có thể làm là yêu cầu học sinh đó ngưng những hành vi đó lại.

v) Phản ứng của giáo viên là biện pháp trực tiếp đơn giản nhưng lại có đủ sức mạnh để tạo cơ sở cho cả hệ quả tích cực nếu được thực hiện một các khéo léo và tiêu cực nếu giáo viên lựa chọn cách áp dụng thiếu thấu đáo, cân nhắc.

Khen thương. Phương pháp này là việc sử dụng những đồ vật thật tương đương để tượng trưng cho hành vi phù hợp. Phần thưởng hiện hữu bao gồm tất cả các cách thức công nhận hoặc phần thưởng cụ thể nào từ giáo viên, có thể ở dưới hình thức vật chất hoặc tinh thần. Việc khen thưởng nào cũng cần được thảo luận kĩ càng về cơ sở của những hình thức thưởng - phạt và cần đảm bảo tính công bằng, khách quan. Hệ thống khen thưởng có thể áp dụng cho học sinh cấp tiểu học là:

i) Hệ thống tem phiếu: Mỗi lần học sinh làm một việc tốt và được cả lớp công nhận hay được điểm cao sẽ được nhận một tem phiếu. Vào những buổi sinh hoạt lớp cuối tuần, học sinh có thể đổi số tem phiếu đã nhận được trong tuần với món quà tương ứng;

ii) Hệ thống bảng mục tiêu - tự đánh giá: Mỗi năm học, giáo viên phát cho học sinh một quyển sổ ghi chép hàng tuần. Trong phần ghi chép hàng tuần có bảng ghi chép cột "mục tiêu" (giáo viên liệt kê ra trước khi bắt đầu một tuần học mới) và cột "tự đánh giá" (học sinh sẽ tự theo dõi và ghi lại). Mỗi buổi sinh hoạt lớp giáo viên sẽ thu lại sổ để xem xét đánh giá hoạt động trong tuần của học sinh. Sau đó, giáo viên có thể lựa chọn những học sinh có thành tích tốt để lựa chọn cách khen thưởng phù hợp.

Hinh phạt kỉ luật. Hình phạt kỉ luật là những tác động dẫn tới những kêt quả trực tiếp và cụ thể dành cho những hành vi không mong đợi từ phía học sinh. Biện pháp hình phạt trực tiểp này dẫn đến những hệ quả rõ ràng và trực tiếp khi học sinh có hành vi không phù hợp. Một trong những biện pháp thông dụng và hiệu quả là thời gian cô lập. Thời gian cô lập chỉ đơn giản là việc mời học sinh có hành vi không phù hợp (sau khi đã nhắc nhở nhiều lần) tới một vị trí dành riêng cho những học sinh gây rối. Để sử dụng hiểu quả biện pháp này thì cần phải cho học sinh biết rõ hành vi cụ thể nào dẫn tới việc áp dụng biện pháp này. Hơn nữa, học sinh cần ý thức được rằng, đây là biện pháp chỉ được sử dụng khi những nỗ lực ứng phó nhẹ nhàng khác không thành công.

Ngoài ra, còn một biện pháp phổ biến khác là đền bù nhiều hơn những gì gây ra. Đây là một biện pháp được sử dụng khi học sinh có hành vi phá hoại của công. Ví dụ, nếu học sinh lật đổ một cái bàn, giáo viên can thiệp bằng cách không chỉ yêu cầu học sinh xếp lại bàn của mình vào đúng chỗ mà còn phải xếp tất cả các bàn trong lớp sao cho thẳng hàng. Nghĩa là học sinh được yêu cầu phải đến bù nhiều hơn những gì mình gây ra, từ đó gửi đi thông điệp mạnh mẽ về hậu quả của hành vi không phù hợp đó.

Phối hợp nhóm. Phối hợp nhóm cũng tương tự biện pháp phần thưởng hiện hữu, tuy nhiên biện pháp này yêu cầu học sinh trong một nhóm phải đạt được tiêu chuẩn hành vi của nhóm đó thì mới được công nhận, khen thưởng. Ví dụ, bạn có thể đặt ra một số hình thức thưởng nếu học sinh trong lớp nhớ giơ tay trước khi phát 
biểu trong giờ học thay vì nói leo, hoặc học sinh chỉ quên không giơ tay vài lần trong ngày. Biện pháp này nhấn mạnh vào áp lực từ các bạn đồng trang lứa khác lên học sinh có hành vi không mong đợi. Yếu tố này chính là lí do làm cho biện pháp này trở nên hiệu quả. Tuy nhiên, cách tiếp cận này nếu không được áp dụng đúng thì có thể làm cho học sinh bị cảm thấy tách biệt, xấu hổ.

Phối hợp với gia đình. Phối hợp với gia đình là tác động quản lí hành vi của học sinh trong môi trường gia đình. Ở mức độ cơ bản thì phối hợp với gia đình là cung cấp thông tin về các con cho cha mẹ để cho cha mẹ có ý thức về những hành vi tiêu cực cũng như tích cực của con cái họ trên lớp. Việc trao đổi này có thể được thực hiện dưới nhiều hình thức khác nhau, ví dụ như qua: điện thoại, tin nhắn, thư điện tử, sổ liên lạc, buổi họp cha mẹ học sinh hoặc một buổi gặp mặt.

Ở một mức độ cao hơn, giáo viên có thể thiết kế một hệ thống kết hợp giữa giáo viên và gia đình học sinh để cha mẹ học sinh có thể thực hiện ở nhà. Điều này đòi hỏi giáo viên phải có những cuộc gặp mặt riêng với các cha mẹ để bàn bạc chi tiết về học sinh, từ đó có thể thiết lập những kế hoạch phù hợp với từng đối tượng học sinh.

\section{Kết luận}

Để giáo dục, dạy học sinh được hiệu quả, giáo viên tiểu học cần được trang bị tốt những kiến thức và kĩ năng quản lí hành vi học sinh, nhận thức được tầm quan trọng của hoạt động này. Không chỉ là những tri thức về chương trình, về sách giáo khoa, về phương pháp, kĩ thuật dạy học, về đánh giá học sinh, trong bối cảnh đổi mới giáo dục phổ thông hiện nay, hơn bao giờ hết, người giáo viên tiểu học cần được quan tâm, đồng hành để giúp họ thực hiện tốt "điều kiện cần" cho dạy học tốt, đó là quản lí hành vi học sinh. Giáo dục theo định hướng phát triển năng lực học sinh gắn liền với những quan điểm, tư duy mới về giáo dục và dạy học. Giáo dục theo tiếp cận đó không dễ làm, dễ thực hiện nếu những thói quen giáo dục, dạy học theo lối cũ không thay đổi. Để làm tốt cái mới đó, giáo viên tiểu học cũng cần đổi mới cách quản lí lớp học, quản lí hành vi học sinh. Nói cách khác, kĩ năng quản lí lớp họ̣c và quản lí hành vi học sinh của giáo viên tiểu học cần được thay đổi và nâng cao. Để làm được điều đó, cô giáo cần hiểu rõ đặc điểm thể chất và tâm lí của học sinh tiểu học, hiểu được hành vi của các em, nắm được những nguyên tắc quản lí hành vi cơ bản gắn với tư tưởng "lấy học sinh làm trung tâm" theo quan điểm giáo dục kiến tạo xã hội. Khi đã có sự thông hiểu trong nhận thức, giáo viên tiểu học có thể xây dựng và thực hiện hiệu quả các biện pháp, chiến lược quản lí hành vi học sinh một cách phù hợp, giúp "kiến tạo" nên những học sinh tích cực, được rèn luyện và phát triển tốt cả về phẩm chất lẫn năng lực, từ đó, họ góp phần đạt được những mục tiêu giáo dục như đã đề ra trong Chương trình Giáo dục Phổ thông 2018.

\section{Lò̀i cảm ơn}

Nghiên cứu này được tài trợ bởi Quỹ Phát triển Khoa học và Công nghệ Quốc gia (NAFOSTED) cho đề tài mã số 503.01-2020.304.

\section{Tài liệu tham khảo}

[1] Ministry of Education and Training, Program of School Education 2018, Hanoi, 2018.

[2] C. Beck, C. Kosnik, Innovations in Teacher Education - A Social Constructivist Approach, NY: State University of New York Press, New York, 2006.

[3] N. V. T. Hang, M. R. Meijer, A. Bulte, A. Pilot, The Implementation of a Social Constructivist Approach in Primary Science Education in Confucian Heritage Culture: The Case of Vietnam, Cultural Studies of Science Education, Vol. 10, No. 3, 2015, pp. 665-693.

[4] R. J. Marzano, J. S. Marzano, D. J. Pickering, Classroom Management that Works: ResearchBased Strategies for Every Teacher, Virginia: Association for Supervision and Curriculum Development, 2003.

[5] S. C. O'Neill, J. Stephenson, Classroom Behavior Management Preparation in Undergraduate 
Primary Teacher Education in Australia: A Web-based Investigation, Australian Journal of Teacher Education, Vol. 36, No. 10, 2011, pp. 35-52.

[6] M. C. Wang, G. D. Haertel, H. J. Walberg, What Helps Students Learn? Educational Leadership, Vol. 51, 1994, pp. 74-79.

[7] W. Doyle, Ecological Management to Classroom Management, in C. M. Evertson, C. S. Weinstein (Eds) Handbook of Classroom Management: Research, Practice, and Competence Issues, Mahwah, N. J, 2006, pp. 97-125.

[8] E. T. Emmer, L. M. Stough, Classroom Management: A Critical Part Ofeducational
Psychology, with Implications for Teacher Education, Educational Psychologist, Vol. 36, No. 2, 2001, pp. 103-112.

[9] J. D. Long, V. H. Frye, Making it Till Friday: A Guide to Successful Classroom Management $\left(3^{\text {rd }}\right.$ ed.), Princeton, N. J: Princeton Book Co., 1985.

[10] J. Dewey, How We Think: A Restatement of the Relation of Reflective Thinking to the Educative Process, Chicago, IL: Henry Regnery, 1933.

[11] L. Vygotsky, Mind in society: The Development of Higher Psychological Processes, Harvard University Press, 1978. 